\title{
Influence of Milling Media on the Mechanical Alloyed W-0.5 wt.\% Ti Powder Alloy
}

\author{
Hadi Jahangiri, ${ }^{1}$ Sultan Sönmez, ${ }^{1,2}$ and M. Lütfi Öveçoğlu' \\ ${ }^{1}$ Particulate Materials Laboratories (PML), Department of Metallurgical and Materials Engineering, \\ Faculty of Chemical-Metallurgical Engineering, Istanbul Technical University, Ayazağa Campus, 34469 Istanbul, Turkey \\ ${ }^{2}$ Department of Mechanical Engineering, Faculty of Engineering, Hakkari University, 30000 Hakkari, Turkey
}

Correspondence should be addressed to Sultan Sönmez; sultansonmez@itu.edu.tr

Received 3 April 2016; Accepted 14 July 2016

Academic Editor: Debdulal Das

Copyright (c) 2016 Hadi Jahangiri et al. This is an open access article distributed under the Creative Commons Attribution License, which permits unrestricted use, distribution, and reproduction in any medium, provided the original work is properly cited.

\begin{abstract}
The effects of milling atmosphere and mechanical alloying (MA) duration on the effective lattice parameter, crystallite size, lattice strain, and amorphization rate of the W- $0.5 \mathrm{wt} . \%$ Ti powders were investigated. W- $0.5 \mathrm{wt} . \%$ Ti powders were mechanically alloyed (MA'd) for $10 \mathrm{~h}$ and $20 \mathrm{~h}$ in a high energy ball mill. Moreover, morphology of the powders for various MA was analyzed using SEM microscopy. Their powder density was also measured by helium pycnometer. The dry milled agglomerated powders have spherical particle, while wet milled powders have layered morphology. Milling media and increasing of milling time significantly reduce the crystallite size. The smallest crystallite size is $4.93 \mathrm{~nm}$ which belonged to the dry milled powders measured by Lorentzian method after 20 hours' MA. However, after 20 hours, MA'd powders show the biggest crystallite size, as big as $57.07 \mathrm{~nm}$, measured with the same method in ethanol.
\end{abstract}

\section{Introduction}

Tungsten (W) alloys are attractive candidate materials for various high temperature structural applications due to their excellent properties such as high melting point, high modulus, high resistance of thermal shock, and low coefficient of thermal expansions (CTE) $[1,2]$. However, alloying of monolithic $\mathrm{W}$ is mandatory for applications which require high strengths at elevated temperatures since mechanical properties of monolithic $\mathrm{W}$ decrease significantly with increasing temperatures [3-11]. Small amounts of nickel (Ni) added as a transition element during mechanical milling (MM) and/or mechanical alloying (MA) activate sintering and enable the fabrication of fully dense W-based alloys and composites at lower temperatures than the usual sintering temperatures of $\mathrm{W}$ [7-13]. Similar to Ni, titanium (Ti) is probably a good candidate in triggering activated-sintering mechanism in $\mathrm{W}$; however, its role as an activator in $\mathrm{W}$ has not been investigated yet. MM and MA are complex processes which involve the optimization of a number of variables to achieve a desired phase or microstructure. Milling media, milling time, ball to powder ratio, milling speed, and starting powder size range influence both the stages of milling and the quality of milled product [14-16].

MA and MM in different milling media result in changing of powder properties and consequently alter mechanical, physical, and thermal properties of the final products. During the MA/MM process, the flattened layers overlap and form cold welds for soft powders which results in the formation of layered composite powder particles consisting of various combinations of the starting ingredients. On the other hand, the work-hardened elements or composite powder particles might be fractured at the same time. These competing events of cold welding (with plastic deformation and agglomeration) and fracturing (size reduction) continue repeatedly throughout the milling period [17-19]. Finally, a refined and homogenized microstructure will be obtained while the composition of the powder particles is of the same proportion of the starting constituent powders [20, 21]. Occasionally, metal powders are milled in a liquid medium also named as wet milling. However, if there is no liquid used during the milling process it is called dry milling $[22,23]$. During wet milling, due to the low efficiency such as retarding crystallite 
refinement attributes to the decrease of the ball's impact force on powders $[17,18,23]$.

Currently, there is no available information in the literature regarding $\mathrm{W}-\mathrm{Ti}$ alloys MAdd in various media such as Ar, ethanol, and isopropyl alcohol (IPA). Moreover, no investigations have been reported on the measurement of the lattice parameter, crystallite size, and lattice strain of the MA'd $\mathrm{W}-0.5 \mathrm{wt} . \% \mathrm{Ti}$ in different medium. The aim of the present study is to investigate the combined effects of mechanical alloying (MA) and various milling media on the W- $0.5 \mathrm{wt} . \%$ Ti powder alloy.

\section{Experimental Procedure}

Elemental tungsten (W) (Eurotungstene ${ }^{\mathrm{TM}}, 99.9 \%$ purity, $45 \mu \mathrm{m}$ average particle size) and titanium (Ti) (Alfa Aesar ${ }^{\mathrm{TM}}$, 99.9\% purity, $45 \mu \mathrm{m}$ average particle size) powders were used in the current study. W powders were premilled for $10 \mathrm{~h}$ in a Spex ${ }^{\mathrm{TM}}$ Duo Mixer/Mill 8000D with a speed of $1425 \mathrm{rpm}$ in a tungsten carbide (WC) vial with $6.35 \mathrm{~mm}$ diameter (1/4 inches) WC balls. Loading and unloading of vials were carried out inside a Plaslabs ${ }^{\mathrm{TM}}$ glove box under purified Ar gas (99.995\% purity) to prevent oxidation during MA. The ball to powder weight ratio (BPR) was $10: 1$.

The premilled $\mathrm{W}$ and elemental Ti powders were blended to constitute the $\mathrm{W}-0.5 \mathrm{wt}$.\% Ti composition and the powder blends were mechanically alloyed (MA'd) in argon atmosphere (dry milling media), in ethanol and isopropyl alcohol (wet milling media) for 10 and $20 \mathrm{~h}$ in a Spex ${ }^{\mathrm{TM}}$ Duo Mixer/Mill 8000D using the same conditions used for premilling: loading and unloading of vials were carried out inside a Plaslabs ${ }^{\mathrm{TM}}$ glove box under purified Ar gas (99.995\% purity) and BPR was $10: 1$.

Morphological characterizations of MA'd W- $0.5 \mathrm{wt} . \% \mathrm{Ti}$ powders were carried out in a Jeol ${ }^{\mathrm{TM}}$ JCM-6000 Benchtop Scanning Electron Microscope attached with a Jeol WX36210DPP EDS unit (Energy Dispersive Spectrometer) using an accelerating voltage of $15 \mathrm{kV}$. Microstructural characterizations of MA'd W- $0.5 \mathrm{wt} . \%$ Ti powders were performed using a Bruker ${ }^{\mathrm{TM}}$ D8 Advance X-ray diffractometer (XRD) $\left(\mathrm{CuK}_{\alpha}\right.$ radiation, $\lambda=1.542 \AA$ ). Crystallite size and strain rates were measured and calculated using TOPAS 5 (Bruker AXS) software using Lorentzian and Gaussian methods. Powder particle size measurements were performed in a Malvern ${ }^{\mathrm{TM}}$ Master-sizer Laser particle size analyzer and in a Microtrac ${ }^{\mathrm{TM}}$ NANO-flex in situ particle size analyzer. True densities of MA'd W- 0.5 wt.\% Ti powders were measured in a helium Pycnometer Micromeritics AccuPyc ${ }^{\mathrm{TM}}$ II 1340.

\section{Results and Discussions}

Figures 1(a)-1(f) are the SEM micrographs showing the morphologies of W- $0.5 \mathrm{wt} . \%$ Ti powders MA'd for $10 \mathrm{~h}$ and $20 \mathrm{~h}$ in different milling media: (a) in Ar (dry milling, Figures 1(a) and 1(b)), (b) in isopropyl alcohol (wet milling, Figures 1(c) and 1(d)), and (c) in ethanol (wet milling, Figures 1(e) and 1(f)). As seen in Figures 1(a) and 1(b), powders MA'd in Ar using dry milling conditions are in the form of agglomerates comprising nearly spherical or spheroidal shaped powder particles having a maximum particle size about $400 \mathrm{~nm}$. Further, MA duration in dry milling conditions has hardly had any effect on the morphology and size of the particles as can be clearly observed in Figures 1(a) and 1(b). On the other hand, as seen in Figures 1(c) and 1(e), during wet milling, layered morphologies formed after MA for $10 \mathrm{~h}$. When MA duration increased to $20 \mathrm{~h}$, particles were shattered into smaller fragments and consequently the particle sizes were reduced (Figures $1(\mathrm{~d})$ and $1(\mathrm{f})$ ). It is interesting to note that the powder particles fabricated during MA in IPA are smaller than those milled in ethanol. Energy dispersive spectroscopy (EDS) spectral analyses revealed the presence of WC regions and/or WC particles in the wet milled powders. In addition, EDS mapping analyses showed homogeneous $\mathrm{Ti}$ distributions within $\mathrm{W}$ particles in all MA'd powders.

XRD patterns of MA'd W- $0.5 \mathrm{wt}$.\% Ti powders are illustrated in Figure 2. The XRD patterns of all MA'd W-0.5 wt.\% Ti powders revealed the presence of the characteristic peaks of the $\mathrm{W}$ (Ti) solid solution phase denoted as the $\mathrm{Ti}_{x} \mathrm{~W}_{(1-x)}$ phase (Bravais lattice: b.c.c.; S.G.: $\operatorname{Im}-3 \mathrm{~m}(229) ; a=0.316 \mathrm{~nm}$; ICDD \#49-1440) and small amounts of the WC phase (Bravais lattice: h.c.p.; S.G.: P-6m2 (187); $a=0.290 \mathrm{~nm}, c=$ $0.283 \mathrm{~nm}$; ICDD \#57-0939).

It is evident from Figure 2 that mechanical alloying, regardless of the milling conditions (wet or dry milling and milling duration), caused the decrease of the peak intensities of W (Ti) solid solution phase and increased peak line broadening. MA'd powders underwent deformation and cold welding caused by continuous collision and fracturing between balls and powders. Thus, the intensity of the diffraction peaks decreased with increasing milling time and became wider due to severe lattice distortion and grain size refinement. However, peak broadening of the $\mathrm{W}-0.5 \mathrm{wt} . \% \mathrm{Ti}$ powders MA'd in dry milling conditions (in Ar) is much more than those MA'd in wet milling conditions (in both IPA and ethanol). This is an expected observation since conditions employed during dry milling are more severe than those during wet milling. In other words, most of the kinetic energy generated by the ball-to-ball and ball-to-vial collisions is absorbed by the liquid media during wet milling as opposed to dry milling where almost all kinetic energy is directly transferred to the powders. As a consequence, it is expected that the crystallite sizes of the dry milled powders are to be much smaller and their lattice deformation amounts are higher than those milled in wet conditions. It is also seen in Figure 2 that, due to the effects of MA, intensive WC contamination appeared after MA [8]. Presumably, these peaks arose from the milling media (vial and balls) owing to the excessive impact energy accumulated during mechanical alloying at a longer duration of $20 \mathrm{~h}$ [13]. Comparing wet and dry MA shows that WC peaks are more intense in wet milling, particularly in IPA [8]. In Ar atmosphere, powders covered whole surface of WC balls and they became smaller. However, in wet milling, the surfaces of the WC balls were clean and during colliding these balls were eroded probably leading to WC contamination in the powders. As shown in Figure 1, small particles of WC are seen in wet MA'd powders and EDS results supported the WC contamination in the long-time 


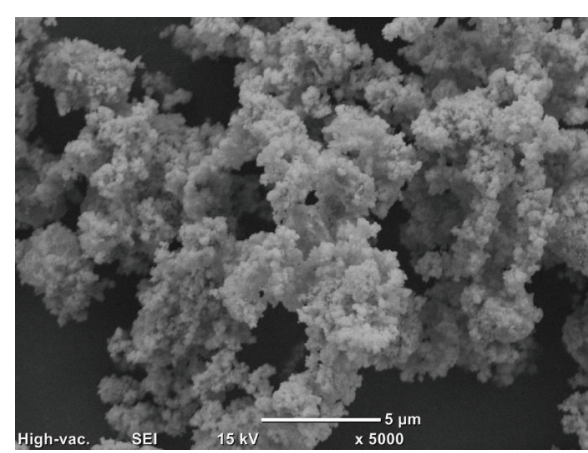

(a) $10 \mathrm{~h} \mathrm{Ar}$

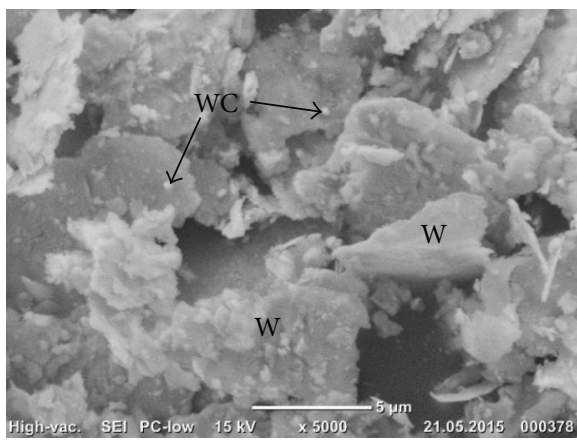

(c) $10 \mathrm{~h} \mathrm{IPA}$

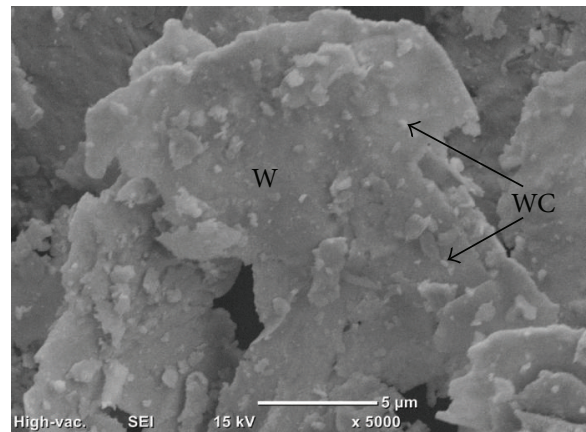

(e) $10 \mathrm{~h}$ ethanol

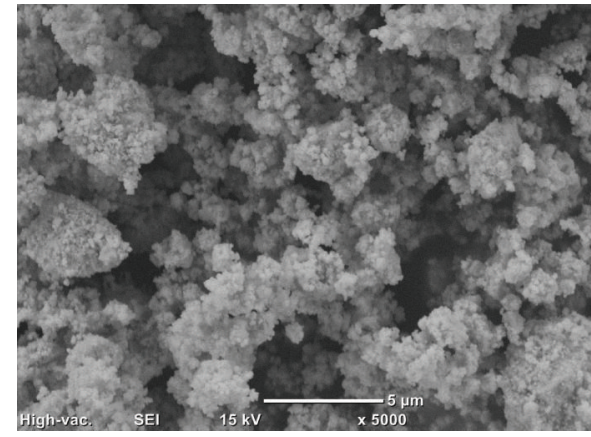

(b) $20 \mathrm{~h} \mathrm{Ar}$

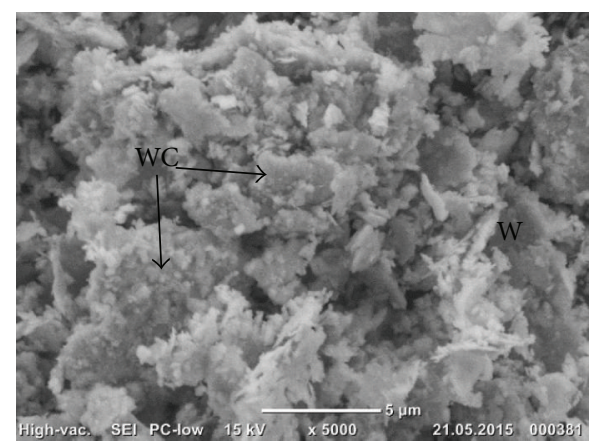

(d) $20 \mathrm{~h} \mathrm{IPA}$

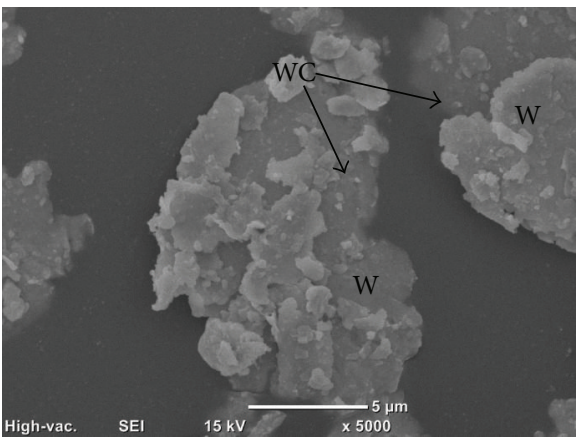

(f) $20 \mathrm{~h}$ ethanol

Figure 1: SEM micrographs of MA'd W-0.5 wt.\% Ti powders in different milling media: (a) MA'd for $10 \mathrm{~h}$ and (b) MA'd for $20 \mathrm{~h}$ in Ar, (c) MA'd for $10 \mathrm{~h}$ and (d) MA'd for $20 \mathrm{~h}$ in isopropyl alcohol (IPA), and (e) MA'd for $10 \mathrm{~h}$ and (f) MA'd for $20 \mathrm{~h}$ in ethanol.

TABLE 1: Crystallite size and lattice strain values of MA'd W- $0.5 \mathrm{wt} . \%$ Ti powders in different milling media.

\begin{tabular}{|c|c|c|c|c|c|c|c|}
\hline \multirow{2}{*}{$\begin{array}{l}\text { Milling media } \\
\text { MA time (h) }\end{array}$} & \multirow{2}{*}{ Pure W } & \multicolumn{2}{|c|}{ Ethanol } & \multicolumn{2}{|c|}{ IPA } & \multicolumn{2}{|c|}{$\mathrm{Ar}$} \\
\hline & & 10 & 20 & 10 & 20 & 10 & 20 \\
\hline Crystallite size L (nm) & 510.47 & 61.00 & 57.07 & 41.30 & 17.27 & 6.53 & 4.93 \\
\hline Crystallite size G (nm) & 436.90 & 31.17 & 30.13 & 20.67 & 13.30 & 5.73 & 5.57 \\
\hline Lattice strain $\mathrm{L}$ & 0.0029 & 0.0357 & 0.3409 & 0.3402 & 1.4823 & 2.1784 & 3.4140 \\
\hline Lattice strain $\mathrm{G}$ & 0.0024 & 0.0436 & 0.6308 & 0.4636 & 1.8015 & 2.5255 & 3.5669 \\
\hline
\end{tabular}

milling. Interestingly, these particles were not found in the SEM micrographs of dry milled powders.

Crystallite size and lattice internal strain determination are the most two important applications in powder X-ray diffractometry for materials characterization. Table 1 shows the variation of the crystallite sizes with milling time (10 and $20 \mathrm{~h}$ ) in three different milling media calculated by Lorentzian and Gaussian methods. High speed ball milling powders result in peak intensity reduction as well as a broadening in full width at half maximum (FWHM). This happens due to a reduction in the crystallite size and an accumulation of the lattice strain. These changes were prominent with variation of 


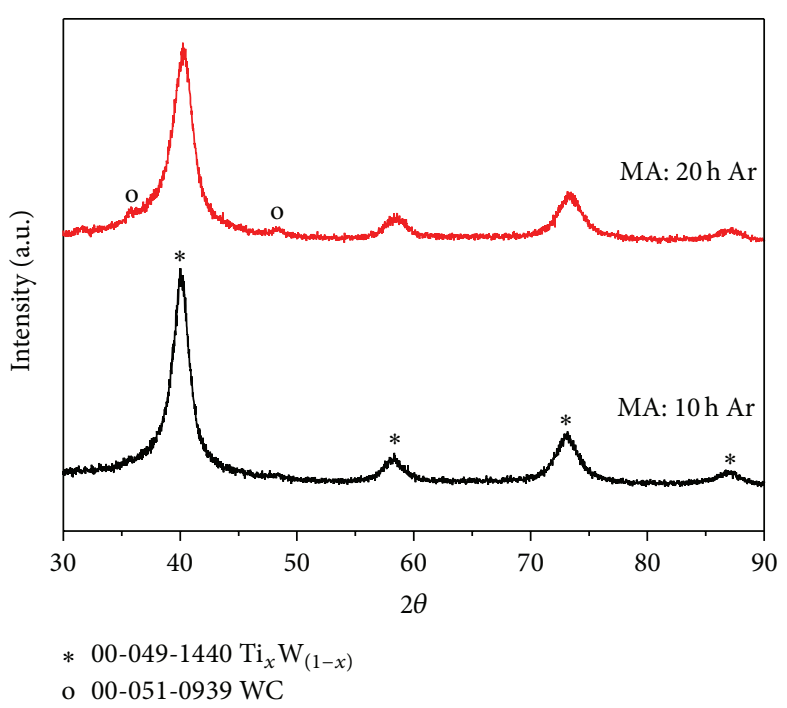

(a) $\mathrm{Ar}$

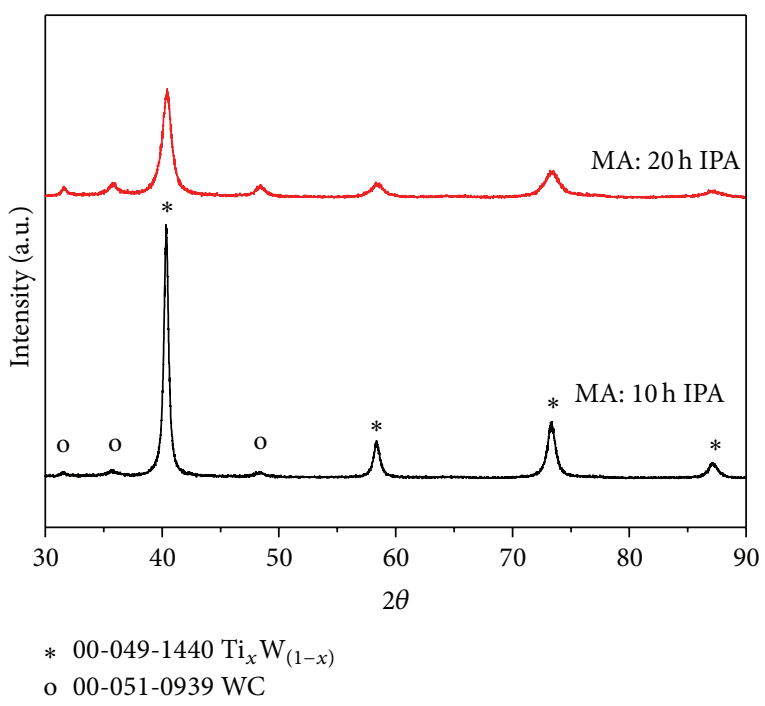

(b) IPA

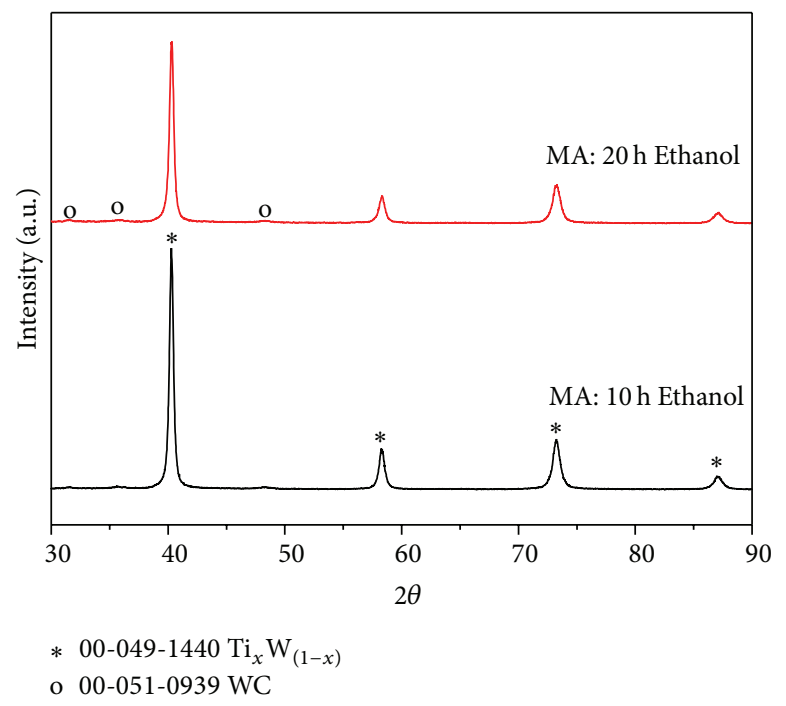

(c) Ethanol

FIGURE 2: XRD patterns of MA'd W-0.5 wt.\% Ti powders in different milling media after $10 \mathrm{~h}$ and $20 \mathrm{~h}$ MA.

milling time and milling media. There was a rapid decrease in crystallite size of $\mathrm{W}-0.5 \mathrm{wt}$. \% Ti powders that occurs from the blended powders and powders mechanically alloyed for $10 \mathrm{~h}$. However, after $10 \mathrm{~h}$ of MA, only a slight further reduction in crystallite size occurs. According to Zuhailawati and Mahani [24] crystallite size measurement in this study was performed using Lorentzian and Gaussian methods. The results indicate that selected MA media were highly effective in reducing crystallite size by increasing milling time. As shown in Table 1, the smallest crystallite sizes belong to the dried milled powders, whereas powders MA'd in ethanol have the largest crystallite sizes. This can be also confirmed with peak broadening shown in Figure 1. Interestingly, Gaussian method shows slightly smaller crystallite sizes compared to Lorentzian method. However, the strain values calculated by Gaussian method are slightly higher than those measured by Lorentzian method.
Figure 3 shows that lattice parameter of the $\mathrm{W}$ (Ti) solid solution phase, that is, " $a$ " values, is maximum after $10 \mathrm{~h}$ MA. Maximum lattice parameters are 3.175, 3.163, and $3.158 \mathrm{~nm}$, respectively, for the $\mathrm{W}$ (Ti) solid solution phase of the powders MA'd for $10 \mathrm{~h}$ in Ar, ethanol, and IPA. Also shown from Figure 3 is that the crystallization rate decreased linearly with increment of MA time from $10 \mathrm{~h}$ to $20 \mathrm{~h}$. The maximum and minimum crystallite rates were measured as $65 \%$ and $91 \%$ after $20 \mathrm{~h} \mathrm{MA}$, respectively, in Ar and ethanol media.

Pycnometer densities (true densities) MA'd W-0.5 wt.\% Ti powders are presented in Table 2. The MA'd W-0.5 wt.\% Ti powders milled in ethanol have the highest densities. This can be also explained with sharp XRD peaks shown in Figure 2(c). On the contrary, the powders MA'd in IPA have the lowest densities. This can be attributed to collisions between vial and balls resulting in continuous increment of WC impurities, 


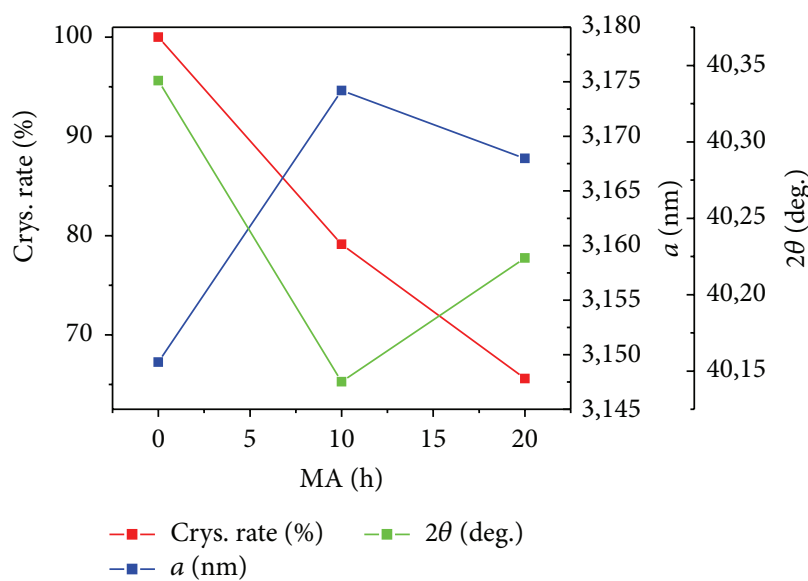

(a) $\mathrm{Ar}$

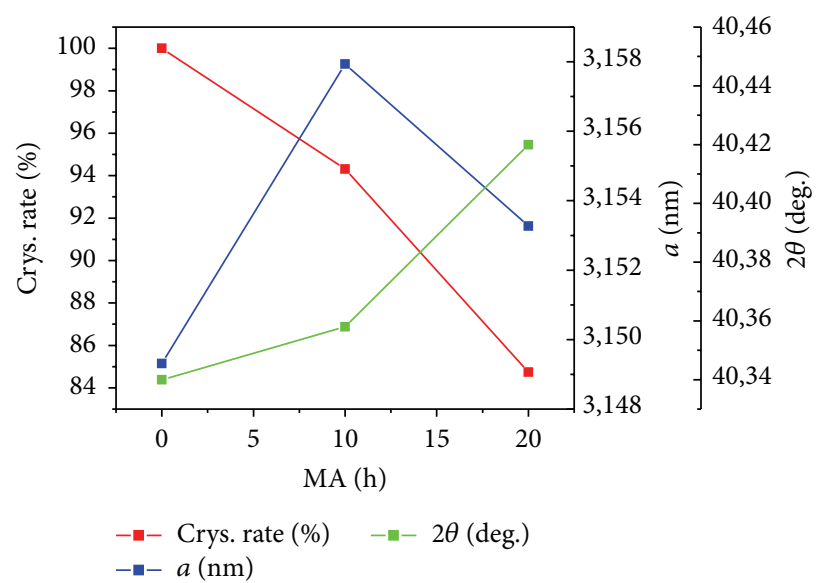

(b) IPA

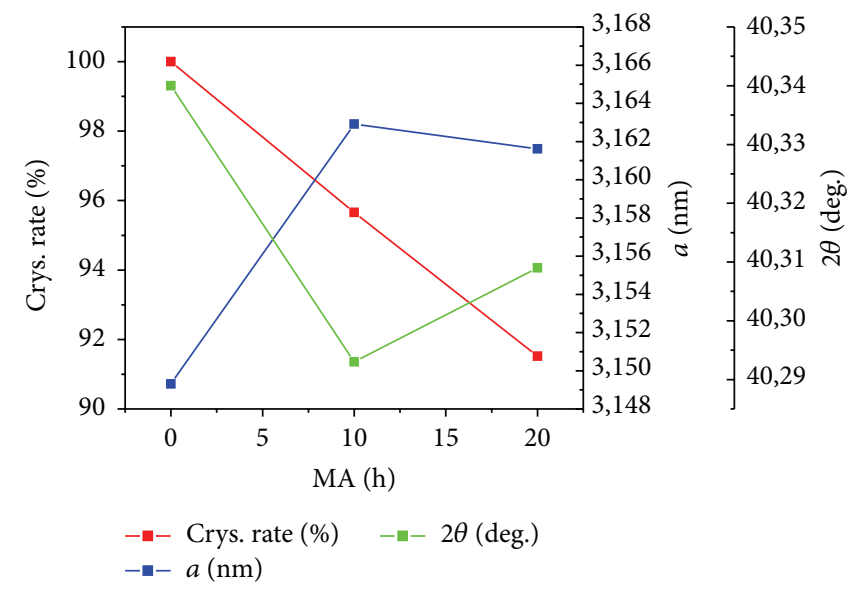

(c) Ethanol

FIgURE 3: Crystallization rates, lattice parameters, and $2 \theta$ (110) degrees of MA'd W- $0.5 \mathrm{wt} . \%$ Ti powders in different milling media after $10 \mathrm{~h}$ and $20 \mathrm{~h} \mathrm{MA}$.

TABLE 2: Pycnometer powder densities of the MA'd W-0.5 wt.\% Ti powders.

\begin{tabular}{lcc}
\hline Milling media & \multicolumn{2}{c}{ Milling time } \\
& $10 \mathrm{~h}$ & $20 \mathrm{~h}$ \\
\hline Ethanol & $18.23 \pm 0.020$ & $18.15 \pm 0.032$ \\
Argon & $15.38 \pm 0.026$ & $14.87 \pm 0.022$ \\
IPA & $12.88 \pm 0.025$ & $12.24 \pm 0.020$ \\
\hline
\end{tabular}

relative to MA time. This is particularly true for the powders milled in IPA media and confirmed by Figure 2 which shows that powders MA'd in IPA have more intense WC peaks than the others. Probably, increment of the WC particles might decrease density of the MA'd W- $0.5 \mathrm{wt} . \%$ Ti powders $[17,18$, 25].

\section{Conclusions}

The morphological and structural changes of MA'd W0.5 wt.\% Ti powders were studied. From this study the following conclusions can be drawn:
(1) The powders MA'd produced by dry milling method for both $10 \mathrm{~h}$ and $20 \mathrm{~h}$ have spherical particle, while wet milling results in layered morphology. Particles which MA'd powders in IPA have are smaller than the ones milled in ethanol. On the other hand, the MA'd powders in argon have the smallest particles.

(2) There was a rapid reduction in crystallite size of $\mathrm{W}-0.5 \mathrm{wt} . \%$ Ti powders between the as-blended powders $(0 \mathrm{~h})$ to $10 \mathrm{~h}$ of MA, while after $10 \mathrm{~h}$ of MA only a slight further reduction in crystallite size was measured by Lorentzian and Gaussian methods.

(3) Milling media were highly effective in reducing crystallite size by increasing milling time. The smallest crystallite size belonged to the dried milled powders. Meanwhile, powders MA'd in ethanol have the largest crystallite sizes.

(4) Crystallization rate decreased linearly with MA time. The maximum and minimum crystallite rates measured were $65 \%$ and $91 \%$, respectively, in $\mathrm{Ar}$ and ethanol media after MA for $20 \mathrm{~h}$. 
(5) MA'd W-0.5 wt.\% Ti powders milled in ethanol have the highest densities, and the powders MA'd in IPA have the lowest.

\section{Competing Interests}

The authors declare that they have no competing interests.

\section{Acknowledgments}

The authors would like to express their appreciation to the Scientific and Technological Research Council of Turkey (TUBITAK) for funding Project no. 114M433. This study was also supported and funded by Scientific Research Projects Unit (BAP) of Istanbul Technical University with Project no. 39007.

\section{References}

[1] E. Lassner and W.-D. Schubert, Properties, Chemistry, Technology of the Element, Alloys, and Chemical Compounds, Kluwer; Vienna University of Technology, Vienna, Austria, 1999.

[2] G.-M. Song, Y.-J. Wang, and Y. Zhou, "The mechanical and thermophysical properties of $\mathrm{ZrC} / \mathrm{W}$ composites at elevated temperature," Materials Science and Engineering A, vol. 334, no. 1-2, pp. 223-232, 2002.

[3] A. Genç, S. Coskun, and M. L. Öveçoğlu, "Decarburization of $\mathrm{TiC}$ in Ni activated sintered $\mathrm{W}-x \mathrm{TiC}(x=0,5,10,15 \mathrm{wt} \%)$ composites and the effects of heat treatment on the microstructural and physical properties," International Journal of Refractory Metals and Hard Materials, vol. 28, no. 3, pp. 451-458, 2010.

[4] A. Genç, M. L. Öveçoğlu, M. Baydoğan, and S. Turan, "Fabrication and characterization of Ni-W solid solution alloys via mechanical alloying and pressureless sintering," Materials and Design, vol. 42, pp. 495-504, 2012.

[5] D. Ağaoğullari, Ö. Balci, H. Gökçe, M. L. Öveçoǧlu, and I. Duman, "Comparative investigations of the activated sintered W-1 wt.\% Ni composites reinforced with various oxide and boride particles," International Journal of Refractory Metals and Hard Materials, vol. 41, pp. 577-584, 2013.

[6] S. Coşkun and M. L. Öveçoğlu, "Effects of $\mathrm{Y}_{2} \mathrm{O}_{3}$ additions on mechanically alloyed and sintered W-4 wt.\% SiC composites," International Journal of Refractory Metals and Hard Materials, vol. 29, no. 6, pp. 651-655, 2011.

[7] Ö. U. Demirkan, A. Genç, and M. L. Öveçoğlu, "Effects of $\mathrm{Al}_{2} \mathrm{O}_{3}$ addition on the microstructure and properties of $\mathrm{Ni}$ activated sintered W matrix composites," International Journal of Refractory Metals and Hard Materials, vol. 32, pp. 33-38, 2012.

[8] A. Genç, E. Ayas, M. L. Öveçoglu, and S. Turan, "Fabrication of in situ $\mathrm{Ni}(\mathrm{W})$-WC nano composites via mechanical alloying and spark plasma sintering," Journal of Alloys and Compounds, vol. 542, pp. 97-104, 2012.

[9] A. Genç, P. Kaya, E. Ayas, M. L. Öveçoğlu, and S. Turan, "Microstructural evolution of mechanically alloyed and spark plasma sintered Ni-W alloy matrix composites," Journal of Alloys and Compounds, vol. 571, pp. 159-167, 2013.

[10] A. Genç and M. L. Öveçoglu, "Characterization investigations during mechanical alloying and sintering of $\mathrm{Ni}$-W solid solution alloys dispersed with WC and $\mathrm{Y}_{2} \mathrm{O}_{3}$ particles," Journal of Alloys and Compounds, vol. 508, no. 1, pp. 162-171, 2010.
[11] D. Agaogullari, Ö. Balcı, O. U. Demirkan et al., "Development of mechanically alloyed and sintered W-1 wt.\% Ni matrix composites reinforced with $\mathrm{TiB}_{2}$," Solid State Phenomena, vol. 194, pp. 194-198, 2013.

[12] S.-M. Hong, J.-J. Park, E.-K. Park et al., "Fabrication of titanium carbide nano-powders by a very high speed planetary ball milling with a help of process control agents," Powder Technology, vol. 274, pp. 393-401, 2015.

[13] P. H. Zhou, L. J. Deng, J. L. Xie, D. F. Liang, and L. Chen, "A study about $\mathrm{Fe}-\mathrm{Ni}$ mechanical alloying process by dry and wet method," Journal of Electronic Science and Technology of China, vol. 2, pp. 164-167, 2005.

[14] I. Özdemir, S. Ahrens, S. Mücklich, and B. Wielage, "Nanocrystalline Al-Al2O3p and SiCp composites produced by highenergy ball milling," Journal of Materials Processing Technology, vol. 205, no. 1-3, pp. 111-118, 2008.

[15] F. Neves, F. M. B. Fernandes, I. Martins, and J. B. Correia, "Parametric optimization of Ti-Ni powder mixtures produced by mechanical alloying," Journal of Alloys and Compounds, vol. 509, no. 1, pp. S271-S274, 2011.

[16] R. B. Schwarz and C. C. Koch, "Formation of amorphous alloys by the mechanical alloying of crystalline powders of pure metals and powders of intermetallics," Applied Physics Letters, vol. 49, no. 3, pp. 146-148, 1986.

[17] E. Lassner and W. D. Schubert, Tungsten: Properties, Chemistry, Technology of the Element, Alloys and Chemical Compounds, Kluwer Academic, New York, NY, USA, 1999.

[18] S.-C. Suryanarayana, "Mechanical alloying and milling," Progress in Materials Science, vol. 46, no. 1-2, pp. 1-184, 2001.

[19] M. Ramezani and T. Neitzert, "Mechanical milling of aluminum powder using planetary ball milling process," Journal of Achievements in Materials and Manufacturing Engineering, vol. 55, no. 2, pp. 790-798, 2012.

[20] M. S. El-Eskandarany, Mechanical Alloying: For Fabrication of Advanced Engineering Materials, William Andrew, 2001.

[21] K. Okada, S. Kikuchi, T. Ban, and N. Otsuka, "Difference of mechanochemical factors for $\mathrm{Al}_{2} \mathrm{O}_{3}$ powders upon dry and wet grinding," Journal of Materials Science Letters, vol. 11, no. 12, pp. 862-864, 1992.

[22] G. Nicoara, D. Fratiloiu, M. Nogues, J. L. Dormann, and F. Vasiliu, "Ni-Zn ferrite nanoparticles prepared by ball milling," Materials Science Forum, vol. 235-238, no. 1, pp. 145-150, 1997.

[23] C. Suryanarayana, Mechanical Alloying and Milling, CRC Press, New York, NY, USA, 2004.

[24] H. Zuhailawati and Y. Mahani, "Effects of milling time on hardness and electrical conductivity of in situ $\mathrm{Cu}-\mathrm{NbC}$ composite produced by mechanical alloying," Journal of Alloys and Compounds, vol. 476, no. 1-2, pp. 142-146, 2009.

[25] C. Politis and W. L. Johnson, "Preparation of amorphous $\mathrm{Ti}_{1-x}$ $\mathrm{Cu}_{x}(0.10<x \leq 0.87)$ by mechanical alloying," Journal of Applied Physics, vol. 60, no. 3, pp. 1147-1151, 1986. 

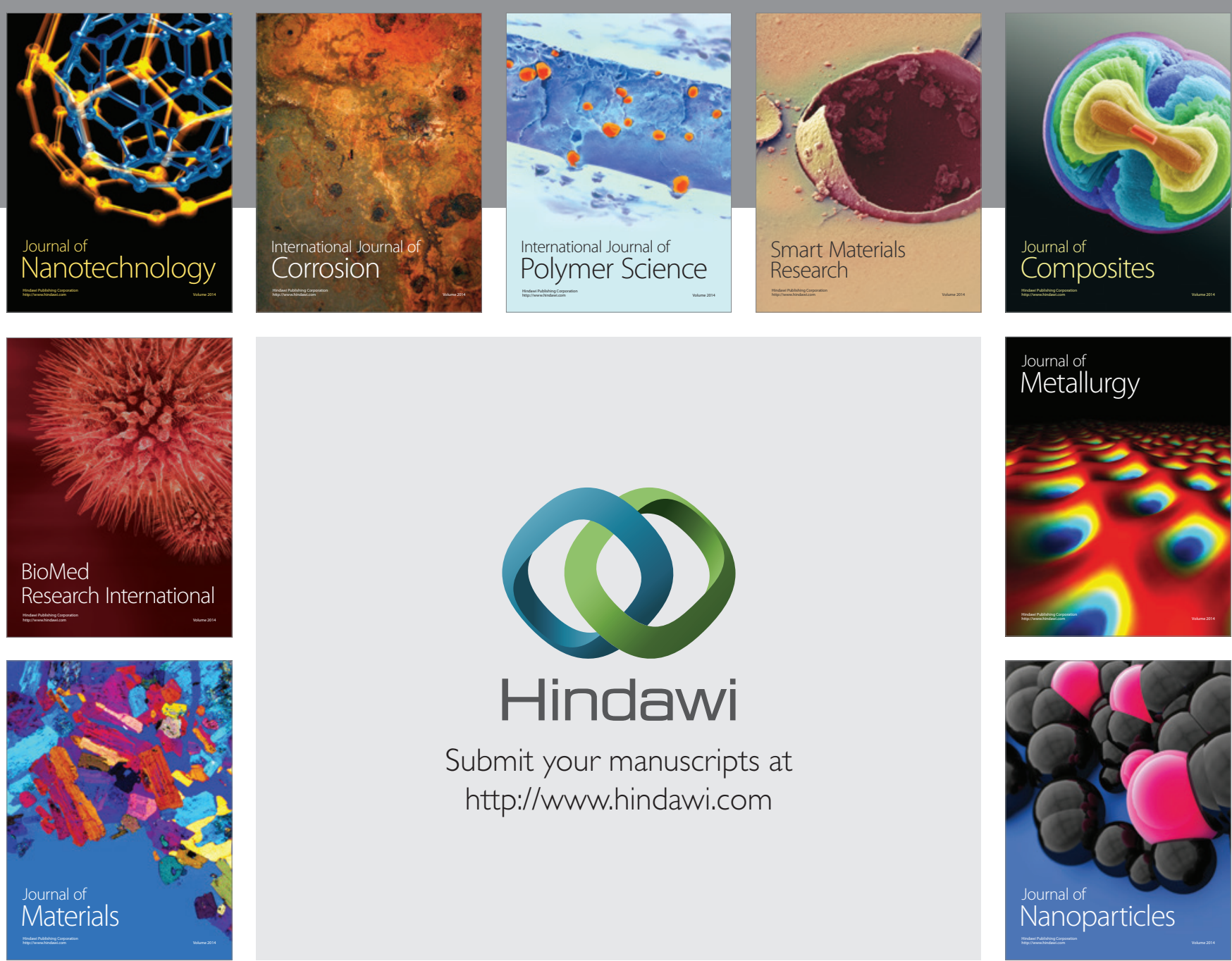

\section{Hindawi}

Submit your manuscripts at

http://www.hindawi.com

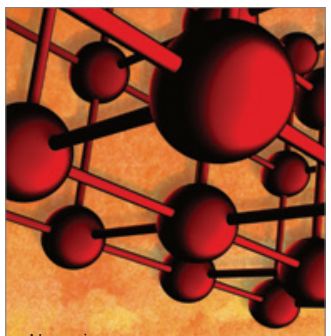

Materials Science and Engineering
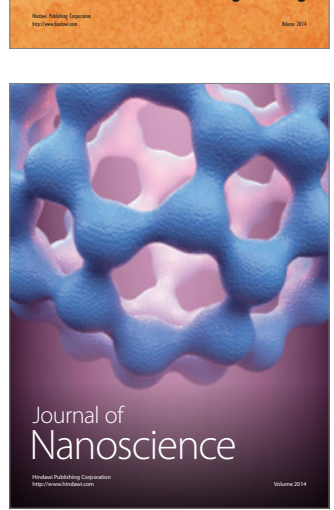
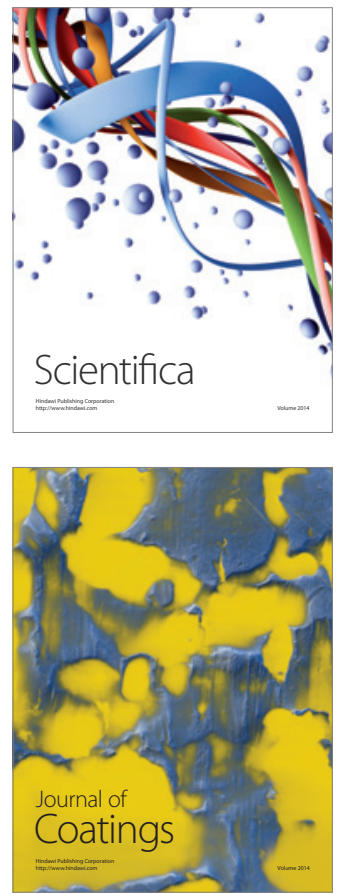
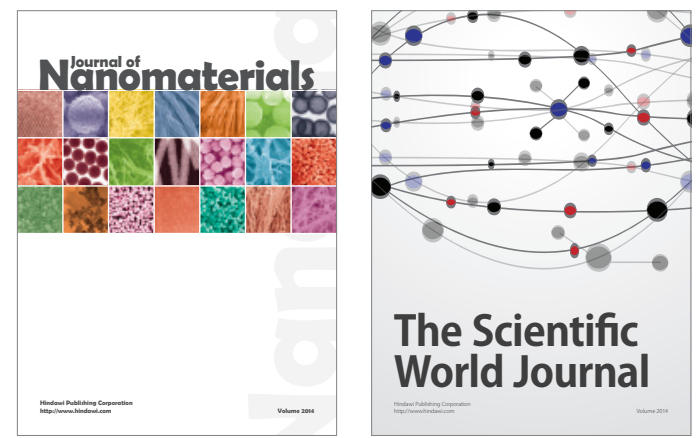

The Scientific World Journal
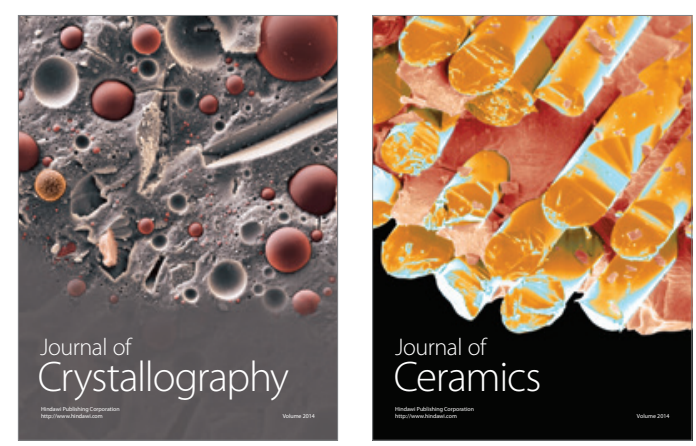
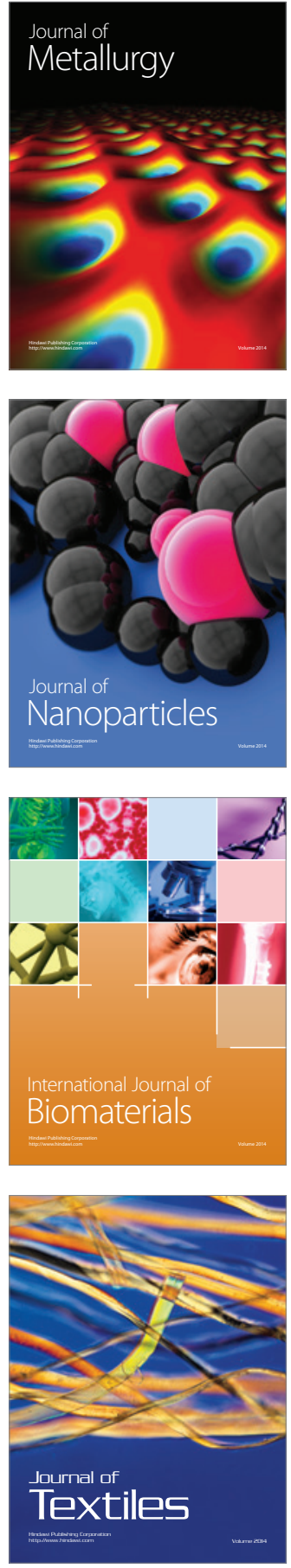